\title{
Efektivitas Dongeng dalam Mengembangkan Karakter Antikorupsi Peserta Didik di Sekolah Dasar
}

\author{
Atikah Mumpuni, Rizki Umi Nurbaeti \\ Universitas Muhadi Setiabudi \\ atikahmumpuni@umus.ac.id
}

\section{Sejarah Artikel}

diterima 22 Oktober 2020 disetujui 20 November 2020 diterbitkan 1 Desember 2020

\begin{abstract}
This research is motivated by the increasing number of corruption cases in Indonesia. Therefore, anti-corruption education which is carried out from an early age is expected to prevent future corruption. Fairy tales are a medium that can be used to develop anti-corruption education in elementary schools. This study aims to measure the effectiveness of fairy tales in anti-corruption in students. The research method was carried out through experiments with a poststest-only control design. Analisis data menggunakan uji $t$ yang dilakukan dengan berbantuan SPSS. Hypothesis test results that have shown the significance level obtained is 0.001 less than 0.05 . Therefore, it can be concluded that fairy tales are proven to be effective in developing anti-corruption characters in students. Suggestions that can be given are fairy tales that can be read and read repeatedly in order to carry out students and the need for the roles of parents and teachers to facilitate and motivate students in reading fairy tales.

Keywords: fairy tales, anti corruption, elementary school
\end{abstract}

\begin{abstract}
Abstrak
Penelitian ini dilatarbelakangi dengan makin maraknya kasus korupsi yang terjadi di Indonesia. Oleh sebab itu, melalui pendidikan antikorupsi yang dilakukan sejak dini diharapkan dapat mencegah terjadinya korupsi dikemudian hari. Dongeng merupakan salah satu media yang dapat digunakan untuk mengembangkan pendidikan antikorupsi disekolah dasar. Penelitian ini bertujuan untuk mengetahui efektivitas dongeng dalam mengembangkan karakter antikorupsi dalam diri peserta didik. Metode penelitian ini dilakukan melalui eksperimen dengan poststestonly control design. Analisis data menggunakan uji t yang dilakukan dengan berbantuan SPSS. Hasil uji hipotesis yang telah dilakukan menunjukkan taraf signifikansi yang diperoleh sebesar 0,001 lebih kecil dari 0,05 . Oleh sebab itu dapat disimpulkkan bahwa dongeng terbukti efektif dalam mengembangkan karakter antikorupsi pada diri peserta didik. Saran-saran yang dapat diberikan yaitu, dongeng yang disajikan perlu dibaca berulangkali agar dapat dipahami peserta didik serta diperlukannya peran orangtua dan guru untuk memfasilitasi dan memotivasi peserta didik dalam kegiatan membaca dongeng.
\end{abstract}

Kata kunci: dongeng, antikorupsi, sekolah dasar 


\section{PENDAHULUAN}

Korupsi merupakan bentuk karakter yang mengindikasikan ketidakjujuran seseorang. Korupsi sangat merugikan lembaga baik swasta maupun pemerintah, bahkan negara. Pemberantasan korupsi perlu diimbangi dari sisi pendidikan untuk mencegah terjadinya korupsi dimasa yang akan datang. Oleh sebab itu, pendidikan antikorupsi sangat penting untuk dilakukan khususnya, pada tingkat Sekolah Dasar.

Permasalahan yang terjadi, khususnya di Sekolah Dasar yang ada di wilayah Kabupaten Brebes adalah belum optimalnya pelaksanaan pendidikan antikorupsi. Hal ini dapat terlihat dari tidak adanya kegiatan khusus yang mendukung pelaksanaan pendidikan antikorupsi. Padahal pendidikan antikorupsi yang dilakukan sejak dini akan dapat membentuk karakter antikorupsia peserta didik dengan lebih baik.

Antikorupsi sendiri merupakan bentuk karakter yang berkaitan dengan nilai-nilai kejujuran. Mumpuni (2018) menyebutkan kejujuran dapat diartikan sebagai 1) kesesuaian antara lahir dan batin; 2) kesesuaian antara perkataan dengan keadaan; dan 3) kebenaran dalam berkata dan bertindak, sehingga selalu dapat dipercaya. Pendidikan antikorupsi di Sekolah Dasar, perlu dilakukan sesuai dengan tahap perkembangan berpikir peserta didik. Salah satunya adalah dengan penggunaan media yang tepat. Dongeng merupakan salah satu media yang dapat digunakan sebagai bahan bacaan dalam mendukung pelaksanaan antikorupsi di Sekolah Dasar.

Dongeng biasanya menceritakan petualangan khayal, dengan tokohtokoh seperti manusia, hewan, hingga

tumbuhan. Hal tersebut ditegaskan oleh Taufina (2016) yang menyebutkan bahwa dongeng diartikan sebagai cerita pendek tentang petualangan khayal denga situasi dan tokoh-tokoh yang luar biasa. Melalui petualangan, alur, dan setting, serta pesan moral yang ditulis dalam dongeng peserta didik dapat mengembangkan karakternya, termasuk karakter antikorupsi. Hal ini sesuai dengan penelitian Rosada (2016) dongeng dengan cerita yang menarik akan memudahkan peserta didik dalam menyerap informasi.

Lebih lanjut, dongeng juga memiliki beberapa manfaat bagi peserta didik. Habsari (2017) menyebutkan beberapa manfaat dari dongeng diantaranya mengajarkan budi pekerti, mengajarkan budaya membaca, dan mengembangkan imajinasi. Berbagai pembelajaran yang didapatkan dari dongeng tentu saja dapat memberikan manfaat positing bagi tumbuh kembang anak.

Disamping, manfaat yang sudah diuraikan sebelumnya, Ardini (2012) menyebutkan dongeng juga dapat mengembangkan kemampuan berkomunikasi peserta didik. Kemampuan berkomunikasi peserta didik ini dapat berkembang karena adanya fantasi yang disajikan dalam dongeng. Melalui fantasi yang disajikan, peserta didik dapat lebih spontan dan berani dalam menyampaikan ide-ide.

Dongeng memiliki berbagai jenis salah satunya adalah fabel. Taufina (2016) menyebutkan bahwa fabel yaitu dongeng yang tokohnya adalah binatang yang berperilaku seperti manusia, misalnya dapat berbicara dan berjalan. Dongeng dalam bentuk fabel dapat digunakan dalam 
mengembangkan karakter antikorupsi dalam diri peserta didik.

Melalui fabel, karakter antar tokoh dalam lebih mudah dikembangkan, sehingga pesan moral, yaitu sikap antikorupsi lebih mudah untuk dipahami peserta didik. Hal ini diperkuat dari hasil penelitian Sumartini, Antara, Magta (2017) bahwa dongeng telah terbukti berpengaruh secara signifikan terhadap pembentukan karakter peserta didik.

Berdasarkan hasil observasi awal yang sebelumnya telah dilakukan, khususnya di Sekolah Dasar yang ada di wilayah Kabupaten Brebes, diketahui bahwa ketersediaan bahan bacaan antikorupsi sangat kurang. Hal ini dapat dilihat dari terbatasnya ketersediaan bahan bahan bacaan di ruang perpustakaan ataupun dimasing-masing ruang kelas. Pengadaan buku dongeng antikorupsi tentu memerlukan pengujian yang ketat, khususnya dari segi keefektivannya dalam mengembangkan karakter antikorupsi peserta didik. Oleh sebab itu, penelitian ini bertujuan untuk mengetahui keefektifan dongeng dongeng dalam mengembangkan karakter antikorupsi sangat perlu untuk dilakukan.
Penelitian ini adalah penelitian eksperimen dengan menggunakan poststest-only control design. Lokasi penelitian dilaksanakan di kelas III SDIT Nurul Hidayah. Populasi penelitian sebanyak 60 peserta didik. Selanjutnya, dengan teknik random sampling didapatkan 30 peserta didik sebagai sampel penelitian. Sampel penelitian mendapat bahan bacaan dongeng antikorupsi dengan judul,
"Momon Monyet Cerdik". Sedangkan 30 peserta didik yang lain mendapat bahan bacaan selain dongeng antikorupsi.

Setelah peserta didik membaca dan mengulas isi dongeng peserta didik akan dibagikan angket penilaian diri yang berkaitan dengan karakter antikorupsi. Pembuatan angket mengacu pada kisi-kisi dan indikator yang terdapat pada Tabel 1.

Tabel 1.

Kisi-Kisi Penilaian Diri Karakter Antikorupsi

\begin{tabular}{lcc}
\hline Nilai Karakter Antikorupsi ${ }^{\star}$ ) & $\begin{array}{c}\text { Nomor Butir Pernyataan } \\
\text { Positif }\end{array}$ & $\begin{array}{c}\text { Negatif } \\
\text { Jujur }\end{array}$ \\
Peduli & $1,2,3$ & $4,5,6$ \\
Mandiri & 7,8 & 9,10 \\
Disiplin & 11,12 & 13,14 \\
Tanggung Jawab & 15,16 & 17,18 \\
Kerja Keras & $19,20,21$ & $22,23,24$ \\
Sederhana & 25,26 & 27,28 \\
Berani & 29,30 & 31,32 \\
Adil & 33,34 & 35,36 \\
\hline
\end{tabular}

*) sumber: Komisi Pemberantasan Korupsi 2017 
Angket penilaian diri dibuat dengan skala empat dalam bentuk skala likert. Langkah terakhir yang dilakukan setelah data terkumpul adalah menganalisis data. Analisis data menggunakan uji $t$ yang dilakukan dengan berbantuan SPSS 22

\section{PEMBAHASAN}

Dongeng "Momon Monyet dilakukan uji efektivitas dongeng Cerdik" adalah dongeng antikorupsi dalam mengembangkan karakter yang sebelumnya telah dikembangkan antikorupsi dalam diri peserta didik. oleh peneliti. Dongeng tersebut Hasil penelitian yang diperoleh dari sebelumnya telah diuji coba, akan kelompok kontrol dan eksperimen, tetapi uji coba yang dilakukan baru tersaji dalam tabel distribusi frekuensi pada tahap uji keterbacaan dongeng. pada Tabel 2 dan 3 sebagai berikut.

Pada uji coba lapangan operasional,

\section{Tabel 2.}

Hasil Postest Kelas Kontrol

\begin{tabular}{cc}
\hline Rentang Skor & Frekuensi \\
\hline $61-67$ & 5 \\
$68-74$ & 4 \\
$75-81$ & 4 \\
$82-88$ & 2 \\
$89-95$ & 8 \\
$96-102$ & 4 \\
$103-109$ & 3 \\
\hline
\end{tabular}

Tabel 3.

Hasil Postest Kelas Eksperimen

\begin{tabular}{cc}
\hline Rentang Skor & Frekuensi \\
\hline $73-80$ & 5 \\
$81-88$ & 5 \\
$89-96$ & 4 \\
$97-104$ & 8 \\
$105-112$ & 4 \\
$113-120$ & 4 \\
\hline
\end{tabular}

Berdasarkan Tabel 2 diketahui bahwa modus skor peserta didik berada pada rentang 89-95, dengan rata-rata skor 84.6. Sementara itu, modus skor pada kelas eksperimen berada pada rentang 97-104, dengan rerata skor 96.6.
Sebelum dilakukan uji hipotesis, dilakukan uji prasyarat hipotesis terlebih dahulu. Uji prasyarat hipotesis yang dimaksud terdiri dari uji normalitas dan uji homogenitas. Hasil uji normalitas dan uji homogenitas tersaji dalam tabel 4 dan 5 sebagai berikut. 
Tabel 4.

Hasil Uji Normalitas

\begin{tabular}{|l|r|r|r|r|r|r|}
\hline \multirow{3}{*}{} & \multicolumn{4}{|c|}{ Kolmogorov-Smirnov ${ }^{\mathrm{a}}$} & \multicolumn{3}{c|}{ Shapiro-Wilk } \\
\cline { 2 - 7 } & Statistic & \multicolumn{1}{c|}{$\mathrm{df}$} & \multicolumn{1}{c|}{ Sig. } & Statistic & \multicolumn{1}{c|}{ df } & \multicolumn{1}{c|}{ Sig. } \\
\hline Skor & .075 & 60 & $.200^{*}$ & .982 & 60 & .534 \\
\hline
\end{tabular}

Tabel 5.

Hasil Uji Homogenitas

\begin{tabular}{|c|c|c|c|}
\hline Levene Statistic & df1 & df2 & Sig. \\
\hline .000 & 1 & 58 & 1.000 \\
\hline
\end{tabular}

Berdasarkan hasil uji normalitas, pada Tabel 4 diketahui bahwa nilai signifikansi yang diperoleh yaitu 0.200 lebih besar dari 0.05 , artinya data yang disajikan berdistribusi normal. Sedangkan pada Tabel 5 pada hasil uji homogenitas, diketahui bahwa nilai signifikansi yang diperoleh sebesar 1,000 lebih besar dari 0.05 , artinya data homogen. Setelah kedua syarat terpenuhi, dilakukan uji hipotesis.

Tabel 6.

Hasil Uji Hipotesis

\begin{tabular}{|c|c|c|c|c|c|c|c|c|c|c|}
\hline & \multicolumn{2}{|c|}{$\begin{array}{c}\text { Levene's Test } \\
\text { for Equality of } \\
\text { Variances } \\
\end{array}$} & \multicolumn{7}{|c|}{ t-test for Equality of Means } \\
\hline & & \multirow[b]{2}{*}{$\mathrm{F}$} & \multirow[b]{2}{*}{ Sig. } & \multirow[b]{2}{*}{$\mathrm{T}$} & \multirow[b]{2}{*}{ Df } & \multirow{2}{*}{$\begin{array}{c}\text { Sig. } \\
(2- \\
\text { tailed })\end{array}$} & \multirow{2}{*}{$\begin{array}{c}\text { Mean } \\
\text { Difference }\end{array}$} & \multirow{2}{*}{$\begin{array}{l}\text { Std. Error } \\
\text { Difference }\end{array}$} & \multicolumn{2}{|c|}{$\begin{array}{l}95 \% \text { Confidence } \\
\text { Interval of the } \\
\text { Difference }\end{array}$} \\
\hline & & & & & & & & & Lower & Upper \\
\hline Skor & $\begin{array}{l}\text { Equal } \\
\text { variances } \\
\text { assumed } \\
\text { Equal } \\
\text { variances } \\
\text { not } \\
\text { assumed }\end{array}$ & .000 & 1.000 & $\begin{array}{l}-3.407 \\
-3.407\end{array}$ & 58.000 & .001 & -12.000 & 3.522 & -19.050 & -4.950 \\
\hline
\end{tabular}

Berdasarkan hasil uji hipotesis yang telah dilakukan didapatkan nilai signifikansi sebesar 0,001 lebih kecil dari 0,05 , sehingga dapat diketahui bahwa $\mathrm{Ho}$ ditolak dan $\mathrm{Ha}$ diterima. Hal ini berarti dongeng yang disajikan terbukti efektif dalam mengembangkan karakter antikorupsi dalam diri peserta didik, yang dapat dilihat dari perbedaan rerata yang cukup signifikan antara kelompok kontrol dengan kelompok eksperimen.
Hasil penelitian ini didukung dengan penelitian sebelumnya yang sudah pernah dilakukan. Fitroh \& Sari (2015) menyebutkan bahwa dongeng merupakan media pengembangan karakter yang efektif pada peserta didik, selain itu dongeng juga merupakan contoh yang baik untuk dapat menumbuhkan karakter peserta didik.

Hal yang sama juga didapatkan dari hasil penelitian Setyowati \& Sufitri (2019) yang menyebutkan bahwa 
dongeng adalah media penerapan karakter yang efektif, hal ini karena peserta didik memerlukan contoh yang baik untuk dapat menumbuhkan karakter dalam dirinya. Cerita yang disajikan dalam dongeng dapat menjadi contoh konkret bagi peserta didik.

Sesuatu yang konkret sangat diperlukan peserta didik diusia Sekolah Dasar, karena masih dalam tahap operasional konkret. Santrock (2011) menyebutkan bahwa tahap operasional konkret adalah tahap perserta didik dapat berpikir atau mengembangkan hal-hal yang bersifat abstrak dengan bantuan sesuatu yang konkret. Karakter adalah sesuatu yang konkret, yang dapat dikembangkan melalui dongeng sebagai media dan contoh nyata bagi peserta didik.

Lebih lanjut, Soetantyo (2013) menyebutkan bahwa melalui kegiatan dongeng, peserta didik dapat mempelajari barbagai karakter yang terdapat dalam cerita. Dengan kata lain, dongeng dapat dikatakan sebagai model peran bagi peserta didik.

Dongeng adalah cerita yang tidak benar-benar terjadi. Hal ini seperti yang dikemukakan oleh Nurgiantoro (2013) bahwa dongeng adalah cerita yang tidak benar-benar terjadi atau tidak masuk akal dan tidak terikat oleh waktu dan tempat. Dengan demikian, dalam sebuah dongeng sering dijumpai penggunaan awalan, seperti zaman dahulu kala, pada zaman dahulu, dsb. Cerita yang disajikan dalam dongeng membuat peserta didik dapat berimajinasi, seolah-olah berada didalam cerita.

Dongeng antikorupsi yang digunakan untuk memberikan perlakukan pada kelas eksperimen memuat sembilan nilai antikorupsi. Kesembilan nilai tersebut mengacu pada Komisi Pemberantasan Korupsi
(2017) yang terdiri dari jujur, peduli, mandiri, disiplin, tangung jawab, kerja keras, sederhana, berani, dan adil. Nilai-nilai karakter antikorupsi tersebut disajikan secara tersurat dan tersirat didalam dongeng, sehingga menyatu dengan cerita dan dapat diterima oleh peserta didik.

Dongeng merupakan salah satu materi yang relevan untuk menyisipkan nilai-nilai antikorupsi. Hal ini seperti yang dikemukakan oleh Murdiono (2016) yang menyebutkan bahwa pendidikan antikorupsi dapat dilakukan oleh guru dengan menyisipkan nilai-nilai antikorupsi dalam materi yang relevan. Melalui dongeng peserta didik akan merasa disuruh, tetapi akan melihat contoh nyata penerapan nilai-nilai antikorupsi melalui cerita yang disajikan.

Habsari (2017) dalam penelitiannnya juga menunjukkan bahwa, strategi pembentukan karakter peserta didik dapat dilakukan dengan pemberian contoh yang didapatkan dari pembiasaan membaca dongeng, pembiasaan mendengarkan dongeng, serta penciptaan lingkungan yang mendukung. Hal ini berarti dongeng sarat akan nilai-nilai karakter, sehingga dapat mengembangkan karakter dari pembacanya.

Pengembangan karakter bagi peserta didik di sekolah dasar, tentu diperlukan implementasi yang cukup kompleks. Hal ini seperti hasil penelitian yang dilakukan oleh Prihatmoho \& Badawi (2020) bahwa pengembangan pendidikan karakter di Sekolah Dasar, diperlukan implementasi intrakulikuler, ekstrakulikuler, dan proses pembelajaran di kelas. Dongeng sendiri, merupakan salah satu bagian yang dapat digunakan dalam pengembangan karakter peserta didik. Akan tetapi, keberhasilan 
pengembangan karakter tersebut harus didukung oleh unsur-unsur yang lain agar lebih optimal.

Orang tua dan guru juga berperan dalam kegiatan membaca dongeng yang dilakukan oleh peserta didik. Fikriyah, Rahaeti, \& Solihati (2020) menyebutkan bahw peningkatan literasi membaca dapat terjadi apabila orang tua atau guru membimbing, mendidik, memberikan contoh, memfasilitasi, dan memotivasi kegiatan peserta didik. Melalui cara ini, diharapkan peserta didik akan dapat menyenangi kegiatan membaca serta memahami bahan bacaan yang disajikan, khususnya bahan bacaan yang berupa dongeng antikorupsi.

Pengembangan karakter antikorupsi pada diri peserta didik, tentu tidak akan dapat berkembang hanya dengan sekali membaca dongeng. Hal ini diperkuan dengan hasil penelitian terdahulu yang dilakukan oleh Rosidah \& Rusmiati (2017) menyebutkan bahwa keberhasilan dongeng dalam mengembangkan karakter dapat terjadi apabila peserta didik fokus memperhatikan isi cerita dan mengenal tokoh yang diceritakan, serta mengingat dan menyimpannya dalam memori otak. Oleh sebab itu, kegiatan membaca dongeng yang dilakukan tidak cukup hanya satu kali, tetapi perlu dilakukan berualang kali, agar peserta didik dapat memahami isi dari dongeng yang disampaikan.

\section{SIMPULAN}

Dongeng terbukti efektif dalam mengembangkan karakter antikorupsi dalam diri peserta didik. Hal ini dapat dilihat dari hasil uji hipotesis yang telah dilakukan, didapatkan signifikansi sebesar 0,001 yang lebih kecil dari 0,05 . Hal ini berarti $\mathrm{Ho}$ ditolak dan $\mathrm{Ha}$ diterima, artinya terdapat perbedaan rerata yang cukup signifikan antara kelompok kontrol dan kelompok eksperimen.

Pengembangan

karakter antikorupsi melalui dongeng tidak cukup dengan sekali membaca saja. Oleh sebab itu, disarankan peserta didik dapat membaca dongeng berkali-kali agar dapat memahami isinya. Peran orang tua dan guru sangat diperlukan dalam mefasilitasi dan memotivasi peserta didik dalam memahami bahan bacaan berupa dongeng antikorupsi yang telah disediakan.

Setelah dilaksanakannya penelitian ini, diharapkan sekolah dapat lebih selektif dalam pengadaan buku dongeng yang dapat mengembangkan karakter antikorupsi dalam diri peserta didik. Selanjutnya, buku dongeng antikorupsi dengan judul "Momon Monyet Cerdik" yang digunakan dalam penelitian ini, sangat direkomendasikan dalam mendukung pengembangan karakter antikorupsi dalam diri peserta didik.

\section{DAFTAR PUSTAKA}

Ardini, P.P. (2012). Pengaruh Dongeng dan Komunikasi Terhadap Perkembangan Moral
Anak Usia 7-8 Tahun. Jurnal Pendidikan Anaki, 1(1), 44-58

Fikriyah, F., Rohaeti, T., Solihati, A. (2020). Peran Orang Tua dalam 
Meningkatkan Literasi Membaca Peserta Didik di Sekolah Dasar. Dwija Cendekia. 4(1) , 94-107

Fitroh, S.F., \& Sari, E.D.N. (2015). Dongeng Sebagai Media Penanaman Karakter Pada Anak Usia Dini. Jurnal PG-PAUD Trunojoyo, 2(2), 95-105

Habsari, Z. (2017). Dongeng Sebagai Pembentuk Karakter Anak. Jurnal Kajian Perpustakaan dan Informasi. Jurnal Kajian Perpustakaan dan Informasi, 1 (1), 21-29

Komisi Pemberantasan korupsi. (2017). Modul Penguatan NilaiNilai Antikorupsi Pada Pendidikan Dasar dan Menengah. Jakarta: Komisi Pemberantasan Korupsi

Murdiyono, M. (2016). Pendidikan Anti Korupsi Terintegrasi dalam Pembelajaran PKn untuk Menanamkan Karakter Kejujuran di SMP. Jurnal IImu Sosial, 15(1), 167-183

Nurgiantoro, B. (2013). Sastra Anak Pengantar Pemahaman Dunia Anak. Yogyakarta: Gadjah Mada University Press

Prihatmojo, A \& Badawi, B. (2020). Pendidikan Karakter di Sekolah
Dasar Mencegah Degradasi Moral di Era 4.0. Dwija Cendekia. 4(1), 142-152

Rosidah, C.T \& Rusmiati, S.H. (2017). Mendongeng Sebagai Media Menumbuhkan Karakter dan Nilai Budaya Bangsa Pada Siswa Sekolah Dasar. Jurnal Pigur, 01 (01), 41-50

Santrock, J. W. (2011). Life Span Development-13 th ed. New York: McGraw-Hill

Soetantyo, S.P. (2013). Peranan Dongeng dalam Pembentuka Karakter Siswa Sekolah Dasar. Jurnal Pendidikan. 14 (1), 44-51

Sufitri \& Setyowati, R. (2019). Pemanfaatan Dongeng dalam Pembelajaran di Sekolah Dasar sebagai Media untuk Membangun Karakter Siswa. Jurnal Keilmuan dan Kependidikan Dasar. 11(1), 7784

Sumartini, L.P.A., Antara, P.A., \& Magta, M. (2017). Pengaruh Metode Dongeng Interaktif Terhadap Karakter Anak Pada Taman Kanak-Kanak Kuncup Harapan Singaraja. Jurnal Pendidikan Anak Usia Dini. 5(1) 